\title{
GENETIC CONSULTATIONS IN NEUROOPHTHALMOLOGY
}

\author{
D. KLEIN \\ Institute of Medical Genetics, University of Geneva, Switzerland
}

The geneticist faced with severe neuroophthalmological conditions should not only establish the prognosis on the basis of probability laws, but also take into consideration the prevailing affective and social situation of these patients and their families.

Huntington's chorea, e.g., manifests itself between 30 and 40 years of age, that is to say, when the patients often have already one or more children, who shall be exposed to the threat of becoming affected until rather an advanced age.

Among other dominant affections, myotonic dystrophy (Steinert) is discussed, which can nowadays be diagnosed in about 1/3 of cases before the first clinical manifestations, owing to slitlamp examination and electromyography. Contrary to Huntington's disease, the affection can be detected at an early stage of life, so that the patients may still be dissuaded from having children.

In the field of ophthalmological conditions, the genetics of uni-and bilateral retinoblastoma, the three types of retinitis pigmentosa (recessive, dominant, sex-linked), the Lowe's and Waardenburg-Klein syndromes, as well as Tay-Sachs disease, are reviewed. As regards the latter condition, the importance of the discovery of a deficiency of hexosaminidase $A$ is pointed out, since the detection of heterozygous carriers, and even prenatal diagnosis, have now become possible for this disease.

The genetic consultations in cases of neurological and ophthalmological conditions are in principle not different from those in other fields. Indeed, we are dealing with disorders following either one of the classical modes of transmission (dominant, recessive, sex-linked) or a multifactorial inheritance, for which we can only establish an empirical risk. However, in no other domain, the genetic advice has to be given in such a careful and tactful manner as in neuroophthalmology, since the information is seldom applying to a single individual but involves the whole family, increasing thus the intrafamilial affective and emotional tension. It is, therefore, not anymore possible to consider the problem under its simple genetic aspect, but also in its psychological and social context.

Among the neurological diseases, the best example for handling the problem in this tactful way is Huntington's chorea, an autosomal dominant affection manifesting itself towards the age of 35 to 40 . Although some progress has been made in the treatment of the disease, there exists still no method of detecting latent heterozygote carriers, so that the affection remains suspended like the sword of Damocles above the head of the offspring.

Another dominant disease, Steinert's myotonic dystrophy, characterized by myotonia, facial and distal myopathy, cataract, hypogonadism, and mental changes, has also become of great importance for genetic counseling. As the disease appears in about $50 \%$ of cases

Proc. 4th Int. Congr. Neurogenet. Neuroophthalmol. (1973)

Acta Genet. Med. Gemellol. (Roma), 23: 115-119

(C) 1974 
after the age of 30 , it is possible for a heterozygote to transmit the gene to his offspring, while he seems still to be healthy. Therefore, the most useful investigation in individuals likely to become affected is slit-lamp examination of the lens (small white opacities localized in anterior and posterior cortical layers and interspersed with scintillating red and green crystals, often not affecting vision) at a stage when muscular and dystrophic symptoms may still be missing. This ocular examination should be followed by electromyography (detection of myotonic discharges), and eventually measurement of serum immunoglobulins. Thus, Bundey et al. (1970) were able to detect among 124 first-degree relatives of 38 index patients with dystrophia myotonica 13 latent heterozygotes ( 6 as a result of clinical examination, 4 by both electromyography and slit-lamp examination, 3 by slit-lamp examination alone).

Let us also mention that the linkage of the locus for dystrophia myotonica with the ABH secretor locus and with the Lutheran blood group locus may have practical application in genetic counseling and prenatal prediction of the disease, since it is possible to determine the secretor status of the fetus by amniocentesis (Renwick et al. 1971).

As for sex-linked inheritance, we have in progressive muscular dystrophy of Duchenne type an instructive example for the detection of heterozygous carriers by the determination of creatinephosphokinase in the serum.

Finally, we would like to quote as an example of autosomal recessive transmission WerdnigHoffmann disease (acute infantile spinal muscular atrophy with lethal issue), where genetic counseling has to be likewise provided with great comprehension. Unfortunately, the detection of latent carriers is still impossible at present, so that in a family with an affected child the expected probability of recurrence is $25 \%$. The tragedy for the family is particularly great, as the children show a normal intellectual development and need extra-affection and care. The maximum life expectancy is, for $95 \%$ of these little patients, 18 months. Pearn and Wilson (1973) have made recently a psychological inquiry in a series of 76 cases of WerdnigHoffmann disease in order to find out how the parents reacted to such a tragic human and genetic situation. It was interesting to note that, although most of them had been told of the recurrence risk, only a minority admitted this knowledge. The authors interpret this rightly as evidence that such bad news had been rejected subconsciously by the parents. Genetic counseling must therefore be presented in the right way and in the right time, so that parents should be able to assimilate it.

As concerns now the ophthalmological affections, we would also like to show by some examples what kind of problems the geneticist may have to face.

Retinoblastoma is a malignant tumour of the retina which appears at about the age of 1-2 years in either a unilateral ( $75 \%$ of cases), or a bilateral $(25 \%)$ form. Its frequency is about $1: 20,000$ births. According to Fraser and Friedmann (1967), 5.5\% of their patients (in a series of 776 blind children) owed their blindness to retinoblastoma.

In a certain number of cases dominant inheritance is proved by transmission through two and more generations. Most of the cases are, however, sporadic forms. The penetrance has been assessed by several authors to be about $80 \%$.

It seems now clear that only 15 to $20 \%$ of unilateral sporadic retinoblastomas are of genetic origin, while the great majority of cases are due to phenocopies. It follows that only 6 to $8 \%$ of the children born to unilaterally affected parents run the risk of becoming likewise affected (Vogel 1967, Fuhrmann and Vogel 1968). 
On the other hand, in the bilateral cases, which are always of genetic origin, the risk of transmission to the offspring is $40 \%$ (as the penetrance is $80 \%$ ).

The risk run by the brothers and sisters is about $4 \%$ in unilateral sporadic cases and $40 \%$ in bilateral cases.

By the way, let us mention that in about half a dozen of cases of retinoblastoma described recently, a partial deletion of the long arm of the D-group chromosome (Dq-) has been found, mostly combined with signs of mental retardation. Other patients with retinoblastoma showed normal karyotype. However, the association between retinoblastoma and Dq- chromosome should not be considered as fortuitous (Wilson et al. 1973).

An important field of genetic counseling in ophthalmology is represented by the pigment degenerations of the retina, where the family history should be investigated most carefully, as there are three different modes of inheritance: autosomal recessive ( $85 \%$ including sporadic cases), autosomal dominant $(10 \%)$, sex-linked recessive (5\%) (Ammann et al. 1965). In all cases of doubtful retinopathia pigmentosa, electroretinography constitutes a very useful method for detecting an underlying degenerative retinal process. Indeed, an ERG may reveal itself abolished soon after birth, although clinical and ophthalmoscopical symptoms will not manifest themselves before puberty.

Of particular interest for genetic counseling is the sex-linked type of retinitis pigmentosa, as the female carriers of the gene can be detected thanks to the presence of a tapetal reflex.

This peculiarity brings sex-linked retinitis pigmentosa close to choroideremia, another progressive chorioretinal condition (abiotrophy), in which the heterozygous state is also detectable through the changes of the fundus of the eye (pigmentation of «pepper and salt » type).

Finally, in a third sex-linked chorioretinal condition, that is ocular albinism, males show, either only at the fundus or in the whole eye-ball, an absence of pigment combined with macular hypoplasia leading to a very low visual acuity (0.1-0.3); nystagmus and sometimes head-nodding complete the symptomatology. The heterozygous females do not suffer any functional disorder but show, nevertheless, alterations at the fundus, in the form of amounts of pigment at the periphery of the retina and a fine perimacular (" stippling ") pigmentation. These female carriers of the gene can, of course, be warned that $50 \%$ of their sons will be affected and $50 \%$ of their daughters become again heterozygous carriers (Franceschetti et al. 1963).

Another type of partial albinism can be seen in the following association (WaardenburgKlein syndrome): white forelock, lateral displacement of the internal canthi and the lacrimal puncta, wide nose-bridge, confluence of the eyebrows (synophris), blue iris or heterochromia, and congenital labyrinthine deafness. The inheritance is irregular dominant (Figure).

In such cases, also the normal family members have to be examined carefully, in order to find out by the mentioned microsymptoms who may be carrier of the gene, which in the offspring may lead to the complete syndrome, including deafmutism.

The oculo-cerebro-renal syndrome (Lowe et al. 1952) develops early in childhood and comprises congenital cataract, often combined with glaucoma and nystagmus, absence of tendon reflexes, psychomotor retardation with osteoporosis, proteinuria, and aminoaciduria. Cryptorchism is also very common.

The inheritance is of the recessive sex-linked type. Female heterozygotes may occasionally show small lenticular opacities. 


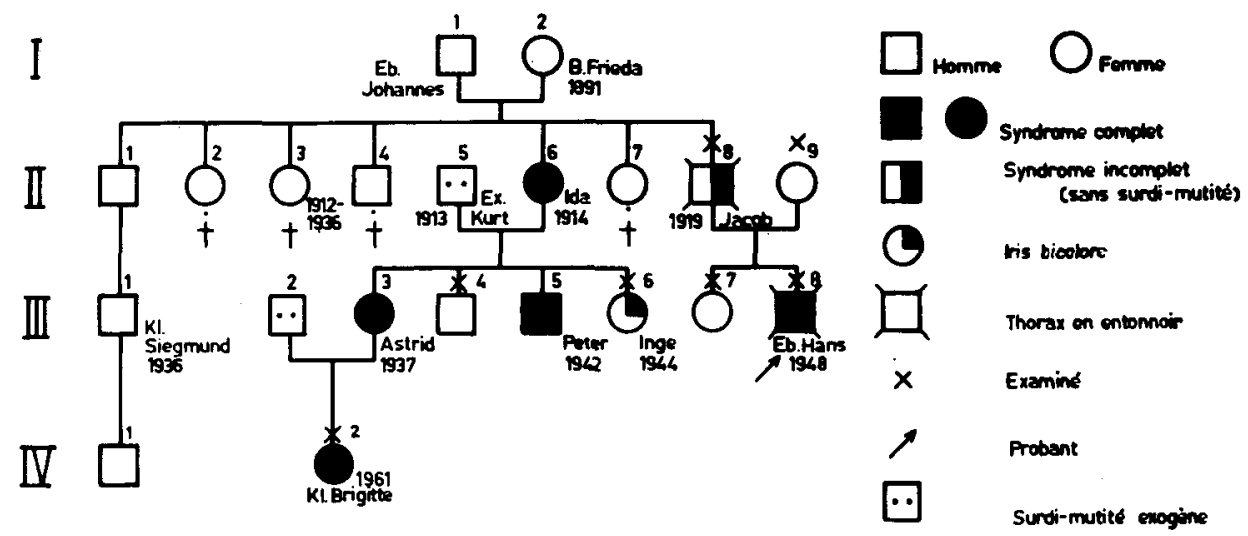

Figure. Pedigree of a family affected with Waardenburg-Klein syndrome. [Personal observation].

We personally had the opportunity to give genetic counseling to a family, the child of which presented Lowe's syndrome. The sibs of the heterozygous mother were particularly glad about our information, as they had got from different sides contradictory answers (Klein and König 1970).

We should like to conclude with the instructive example of Tay-Sachs disease, where the discovery of the underlying biochemical defect, that is, cerebral (intraneuronal) accumulation of a specific ganglioside $\left(\mathrm{GM}_{2}\right)$, and the finding of a lack of an enzyme (hexosaminidase $\mathrm{A}$ ) have made possible to diagnose the disease not only before its clinical manifestation, but already at birth, and even prenatally (Okada and O'Brien 1969, O'Brien et al. 1970, Okada et al. 1971).

To end this chapter with an optimistic note, we would like to speak of Leber's optic atrophy, which still presents a puzzling behaviour as concerns its genetic transmission. Indeed, although it behaves more or less like a sex-linked disease, it has never been possible to observe the transmission of the disease through an affected father. That means that an affected man is always at the end of a line of descent. All the female carriers derive their carrier state from their mother, and not from their father. On the other hand, the sisters of affected men are more often carriers, affected or not, than could be expected according to the theoretical proportion.

Therefore, in cases of genetic counseling, an affected patient can be reassured that he will not transmit the gene to his offspring; but his unaffected sisters may very well give rise again to a child affected with Leber's disease, which is obviously a matter of great concern. 


\section{REFERENCES}

Ammann F., Klein D., Franceschetti A. 1965. Genetic and epidemiological investigations on pigmentary degeneration of the retina and allied disorders in Switzerland. J. Neurol. Sci., 2: 183-196.

Bundey S., Carter C.O., Soothill J.F. 1970. Early recognition of heterozygote for the gene for dystrophia myotonica. J. Neurol. Neurosurg. Psychiatry, 33: 279-293.

Franceschetti A., François J., Babel J., de Rouck A., Dieterle P., Forni S., Klein D., Ricci A., Verriest G. 1963. Les Hérédodégénérescences Choriorétiniennes. 2 vol.; Paris: Masson \& Cie.

Fraser C.R., Friedmann A.I. 1967. The Causes of Blindness in Childhood. Baltimore: Johns Hopkins Press.

Fuhrmann W., Vogel F. 1968. Genetische Familienberatung. Berlin-Heidelberg: Springer-Verlag.

Klein D. 1947. Albinisme partiel (leucisme) accompagné de surdi-mutité, d'ostéo-myodysplasie, de raideurs articulaires congénitales multiples et d'autres malformations congénitales. Arch. Julius Klaus Stift. Vererbungsforsch., 22: 336-342.

Klein D. 1950. Albinisme partiel (leucisme) avec surdi-mutité, blépharophimosis et dysplasie myoostéo-articulaire. Helvet. Paediatr. Acta, 5: 38-58.

Klein D. 1958. La Dystrophie Myotonique (Steinert) et la Myotonie Congénitale (Thomsen) en Suisse. J. Genet. Hum., Suppl. vol. 7.

Klein D. 1969. Les consultations génétiques en ophtalmologie. Ophthalmologica, 158: 521-540.

Klein D., König H. 1970. Ophthalmological and genetic considerations on a case of Lowe's syndrome. J. Genet. Hum., 18: 191-195.
Klein D. 1972. La consultation génétique. Bull. Acad. Suisse Sci. Med., 28: 250-265.

Lowe C.U., Terrey M., MacLachlan E.A. 1952. Organic-aciduria, decreased renal ammonia production, hydrophthalmos, and mental retardation. Am. J. Dis. Child., 83: 164-184.

O'Brien J.S., Okada S., Chen A., Fillerup D.L. 1970. Tay-Sachs disease: detection of heterozygotes and homozygotes by serum hexosaminidase assay. New Engl. J. Med., 283: 15-20.

Okada S., O'Brien J.S. 1969. Tay-Sachs disease: generalized absence of a beta-D-N-acetylhexosaminidase component. Science, 165: 698-700.

Okada S., Veath M.L., Leroy J., O'Brien J.S. 1971. Ganglioside $\mathrm{GM}_{2}$-storage diseases: hexosaminidase deficiencies in cultured fibroblasts. Am. J. Hum. Genet., 23: 55-61.

Pearn J.H., Wilson J. 1973. Acute Werdnig-Hoffmann disease: acute infantile spinal muscular atrophy. Arch. Dis. Child., 48: 425-430.

Renwick J.H., Bundey S.E., Ferguson-Smith M.A., Izatt M.M. 1971. Confirmation of linkage of the loci for myotonic dystrophy and $\mathrm{ABH}$ secretion. J. Med. Genet., 8: 407-416.

Vogel F. 1967. Genetic prognosis in retinoblastoma. Mod. Trends Ophthalmol., 4: 34-42.

Waardenburg P.J. 1951. A new syndrome combining developmental anomalies of the eyelids, eyebrows and nose root with pigmentary defects of the iris and head hair and with congenital deafness. Am. J. Hum. Genet, 3: 195-253.

Wilson M.G., Towner J.W., Fujimoto A. 1973. Retinoblastoma and D-chromosome deletions. Am. J. Hum. Genet., 25 : 57-61.

Prof. D. Klein, Institut de Génétique Médicale, 8 chemin Thury, 1206 Genève, Switzerland. 